\title{
Design and Fabrication of Pneumatic Powered Two Wheeler
}

\author{
P.Madhu Raghava ${ }^{1}$, Asst Prof, T.Lokesh,(B.Tech) ${ }^{2}$, M.Ravichandra ${ }^{3}$, \\ O.Jayaramudu ${ }^{4}$ \\ 1,2,3,4 Dept.of Mechanical Engineering SREC, NANDYAL
}

\begin{abstract}
This project is design, fabrication and development of a design and fabrication of pneumatic bicycle it is rear wheel drive. The conceptual design of this model is taken from manually operated bicycle. The complete body looks like a bicycle in which manual operation followed this product is a pneumatic vehicle, useful for handicapped people, and also normal persons. The power transmission takes place from rear wheel through chain drive. The entire arrangement of power transmission by means of connecting rod of the actuator is taken along with the chain sprocket. When the cylinder is connected to, it would give a driving force due the pressure at which air is sent. Only one person is allowed on the bicycle at any time. The material, mild steel is choose as a main structure fastening by joint, and main components of this project is , air cylinder, solenoid valve, electrical control unit, pneumatic actuator, power transmitting chain, sprocket wheel, two wheeler rear wheel components of model attach by welding, part by part create then be fabricating together. At the end of the project, the model is tested by several people and their comment then being recorded and performed some tests. The concept of compressed air bicycle in practice reduces the air pollution to large extend as its exhaust is nothing but air.
\end{abstract}

Key words: bicycle, solenoid valve, mildsteel, pwer transmission, cylinder, compressed air.

\section{INTRODUCTION}

Fossil fuels (i.e., petroleum, diesel, natural gas and coal) which meet most of the world's energy demand today are being depleted rapidly. Also, their combustion products are causing global problems, such as the greenhouse effect, ozone layer depletion acid rains and pollution which are posing great danger for environment and eventually for the total life on planet. These factors are leading automobile manufactures to develop cars fuelled by alternatives energies. Hybrid cars, Fuel cell powered cars, Hydrogen fuelled cars will be soon in the market as a result of it One possible alternative is the air powered vehicle. Air, which is abundantly available and is free from pollution, can be compressed to higher pressure at a very low cost, is one of the prime option since atmospheric pollution can be permanently eradicated. We hereby present Design and fabrication of pneumatic bicycle and proceed with sense of awakening ideas on ECO FRIENDLY VEHICLES believing that only we engineers can bring such an optimizing product in the world, so get ready to Change your future with today energy.

\section{IDEA DEVELOPMENT}

A tricycle is an air-operated one-person capacity vehicle that is specially designed for low mobility. It is generally used by those who have difficulty walking or moving frequently from one place to another (Handicapped people). Tricycles are available in variety of designs, those intended for outdoor use. A tricycle is different from a manually operated wheel chair as source of supply is air motor which utilize freely available air as the working medium that is to transmit power from the source to destination.

\section{CONCEPT DESIGN}

A tricycle have 2 wheels powered by a 1.3 hp pneumatic Ratchet which is fixed at bottom of the main frame. A tricycle is rear wheel drive get the power from ratchet by sprocket and chain drive. This tricycle provides all the controls for driving to the driver. Some people are a little worry about purchasing a automated tricycle as compared to manually operated tricycle because it will be difficult to operate. In fact, the control console makes it quite simple, once a person gets the feel for it. Power scooters are also equipped with disc brake system, so stopping is simple, safe and comfortable. There is no automatic tricycle available in market for handicapped people, which can reduce their manual effort, this core idea makes the project unique. The problem is, most of that tricycle is not flexible.

\section{TYPE OF TRICYCLE}

There are two categories in which tricycle is divided.

i. Human powered tricycle

ii. Motorized tricycle

The main categories of bicycles in relation to their intended use are: 
i. Road are designed for traveling at speed on paved roads.

- Touring bicycles are designed for bicycle touring and long journeys. They are durable and comfortable, capable of transporting baggage, and have a wide gear range.

- Randonneur or Audax bicycles are designed for randonnées or brevet rides, and fall in between racing bicycles and those intended for touring in terms of frame geometry and weight.

- Hybrid bicycles are a compromise between the mountain and racing style bicycles which replaced European-style utility bikes in North America in the early 1990s. They have a light frame, medium gauge wheels, and derailleur gearing, and feature straight or curved-back, touring handlebars for more upright riding.

- Flat bar road bikes are road bikes fitted with mountain bike-style shifters, brake levers and a flat handlebar. They fit into the continuum between hybrids and road bikes.

\section{Motorized tricycle}

A motorized bicycle is a bicycle with an attached motor and transmission used either to power the vehicle unassisted, or to assist with pedalling. Since it always retains both pedals and a discrete connected drive for rider-powered propulsion, the motorized bicycle is in technical terms a true bicycle, albeit a power-assisted one. However, for purposes of governmental licensing and registration requirements, the type may be legally defined as a motor vehicle, motorcycle, moped, or a separate class of hybrid vehicle. Powered by a variety of engine types and designs, the motorized bicycle formed the prototype for what would later become the motorcycle.

\section{LITERATURE REVIEW}

The simplicity in design, durability and compact size of pneumatic systems make them well suited for mobile applications. Pneumatic control system plays very important role in industrial system owing to the advantages of low cost, easy maintenance, cleanliness, readily available, and cheap source, etc. [1]. A particularly well suited application for vehicle operating on compressed air is material handling and for visitors in industry. Compressed air storage energy (CASE) is a promising method of energy storage, with high efficiency and environmental friendliness [2].The moped has top speed of about $18 \mathrm{mph}$ and could go 7 miles before its air pressure ran out .An inventor, JemStansfield, has been able to convert a regular scooter to a compressed air moped [3]. Behavior of compressed air Compressed air is clean, safe, simple and efficient. There are no dangerous exhaust fumes of or other harmful by products when compressed air is used as a utility. It is a noncombustible, non-polluting utility. When air at atmospheric pressure is mechanically compressed by a compressor, the transformation of air at 1 bar (atmospheric pressure) into air at higher pressure (up to 414 bar) is determined by the laws of thermodynamics. They state that an increase in pressure equals a rise in heat and compressing air creates a proportional increase in heat. Boyle's law explains that if a volume of a gas (air) halves during compression, then the pressure is doubled. Charles' law states that the volume of a gas changes in direct proportion to the temperature [4].the air expands outward with so much energy that the balloon explodes. Compressing a gas into a small space is a way to store energy. When the gas expands again, that energy is released to do work. That's the basic principle behind what makes an air cargo[5]. in which the importance of the impact of the fossil fuels in the present and future generations is explained which led them to design a new vehicle which runs by renewable energy sources. Compressed air vehicle are more suitable for low speed, short range and flammable environment [6, 7].The first compressed-air vehicle was devised by Bompas, a patent for a locomotive being taken out in England in 1828. There were two storage tanks between the frames, with conventional cylinders and cranks. It is not clear if it was actually built.

\section{HISTORY}

There were several unverified, claims for the invention of machines like bicycle. In 1493, the earliest comes from a sketch which being attributed to Gian Giacomo Caprotti. Primitive version of a bicycle sketch was surfaced in 1974 by Leonardo da Vinci. The Celerifere was built by Comte de Sicrac, in 1791. The Celerifere, purportedly was a hobby horse with two wheels instead of a rocker. A rider would power forward by running or walking with their feet and then glide on the celerifere. In 1817, German Baron, Karl Drais Von Sauerbronn invented a laufmaschine, means a running machine, an improved two-wheel version of the celerifere,. It was variously called the running machine, velocipede, Draisienne and Dandy horse. It had a steer-able front wheel directing the front wheel a bit. In 1839, Kirkpatrick MacMillan built the first mechanically propelled 2-wheel vehicle. In Velocipedes, the system of driving levers and pedals that allows rider to propel the machine with feet off the ground was introduced by him. In 1817 Baron von Drais invented a walking machine that would help him get around the royal gardens faster: two same-size in-line wheels, the front one steerable, mounted in a frame which you straddled. The device was propelled by pushing your feet 
against the ground, thus rolling yourself and the device forward in a sort of gliding walk. The machine became known as the Draisienne or hobby horse. It was made entirely of wood. This enjoyed a short lived popularity as a fad, not being practical for transportation in any other place than a well maintained pathway such as in a park or garden.

\section{OBJECTIVES}

I. Fabrication model development of single rider automatically operated tricycle.

II. By some modification and improvement inside the engine increase the power and efficiency of motor.

\section{METHODOLOGY}

\section{Literature study}

Make review on other model and focusing on how to make it simple

and relevance to the project title.

\section{Conceptual design}

Sketching several type of design based on concept that being choose.

State the dimension for all part.

\section{Materials Selection}

Selected the true material based on model design and criteria.

Light, easy to joining and easy to manufacture.

Assemble all the part to the design.

\section{Fabrication model refinement.}

Fabricate the tricycle according to the main frame and design.

Refinement at several part of joining and sharp edge.

\section{Performance testing.}

Speed.Power developed.

\section{Documentation}

Preparing a report for the project.

\section{PROJECT FLOW CHART}

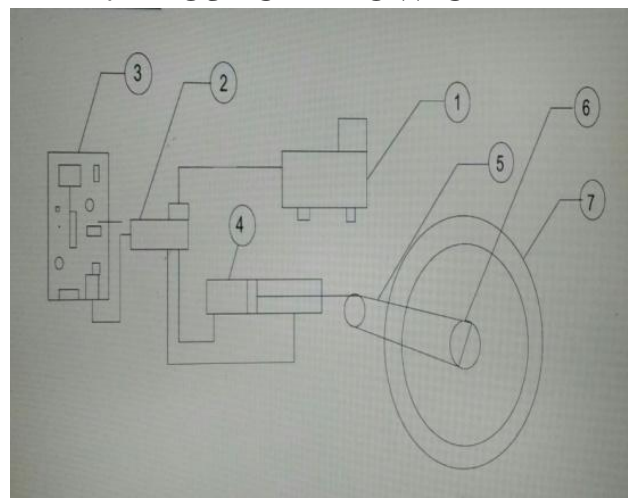

2. Solonoid Valve

3. Electrical Control Unit

4. Pnemautic Acctuater

5. Poewr Transmiting Chain

6. Sprocket Wheel

7. Two Wheeler Rear Wheel

\section{SOLONOID VALVE}

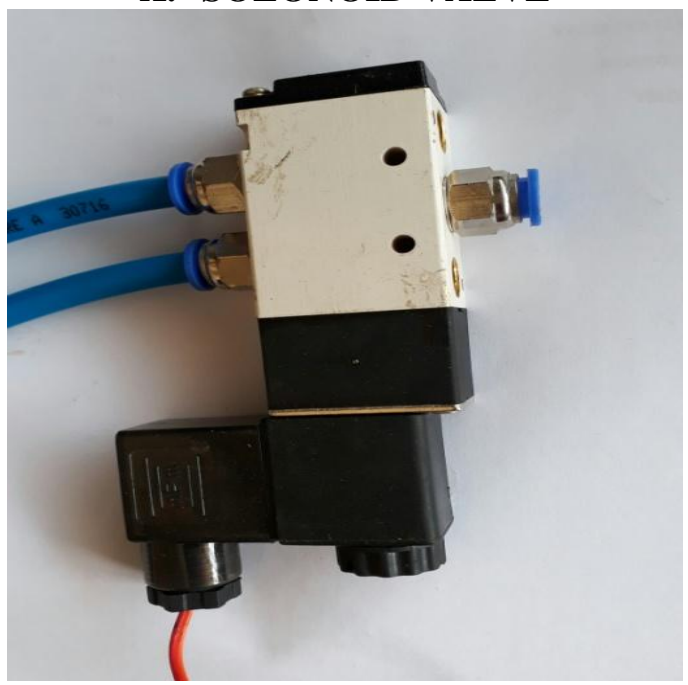

XI. TRANSMISSION SYSTEM

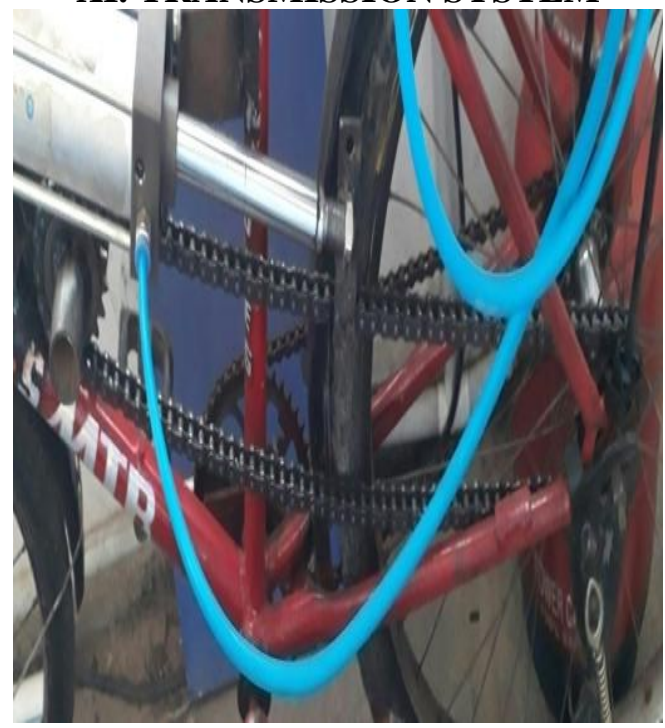

1. Air Cylinder 


\section{SPROCKET WHEEL}

A sprocket or sprocket-wheel is a profiled wheel with teeth, cogs, or even sprockets that mesh with a chain, track or other perforated or indented material. The name 'sprocket' applies generally to any wheel upon which radial projections engage a chain passing over it. It is distinguished from a gear in that sprockets are never meshed together directly, and differs from a pulley in that sprockets have teeth and pulleys are smooth. Sprockets are used in bicycles, motorcycles, cars, tracked vehicles, and other machinery either to transmit rotary motion between two shafts where gears are unsuitable or to impart linear motion to a track, tape etc. Perhaps the most common form of sprocket may be found in the bicycle, in which the pedal shaft carries a large sprocket-wheel, which drives a chain, which, in turn, drives a small sprocket on the axle of the rear wheel. Early automobiles were also largely driven by sprocket and chain mechanism, a practice largely copied from bicycles.

Sprockets are of various designs, a maximum of efficiency being claimed for each by its originator. Sprockets typically do not have a flange. Some sprockets used with timing belts have flanges to keep the timing belt cantered. Sprockets and chains are also used for power transmission from one shaft to another where slippage is not admissible, sprocket chains being used instead of belts or ropes and sprocket-wheels instead of pulleys. They can be run at high speed and some forms of chain are so constructed as to be noiseless even at high speeds

chain or bush roller chain is the type of chain drive most commonly used for transmission of mechanical power on many kinds of domestic, industrial and agricultural machinery, including conveyors, wire- and tube-drawing machines, printing presses, cars, motorcycles, and bicycles. It consists of a series of short cylindrical rollers held together by side links. It is driven by a toothed wheel called a sprocket. It is a simple, reliable, and efficient means of power transmission.

\section{FLUID POWER ACTUATORS:}

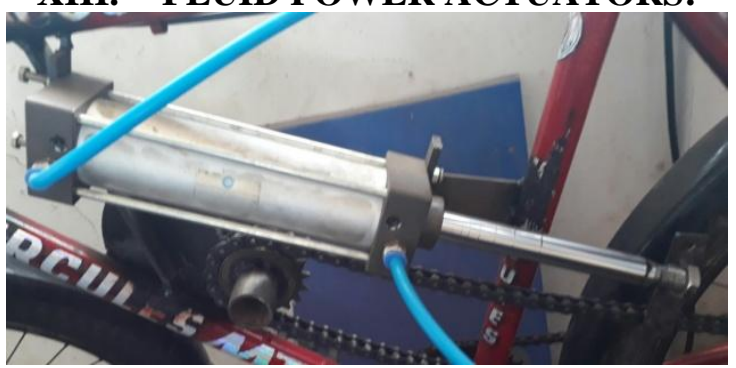

Both hydraulic and pneumatic power may be used to drive an actuator, usually the larger and more powerful types. As their internal construction is generally similar (in principle, if not in size) they are often considered together as fluid power actuators. Fluid power actuators are of two common forms: those where a linear piston and cylinder mechanism is geared to produce rotation (illustrated), and those where a rotating asymmetrical vane swings through a cylinder of two different radii. The differential pressure between the two sides of the vane gives rise to an unbalanced force and thus a torque on the output shaft. Vane actuators require a number of sliding seals and the joins between these seals have tended to cause more problems with leakage than for the piston and cylinder type.

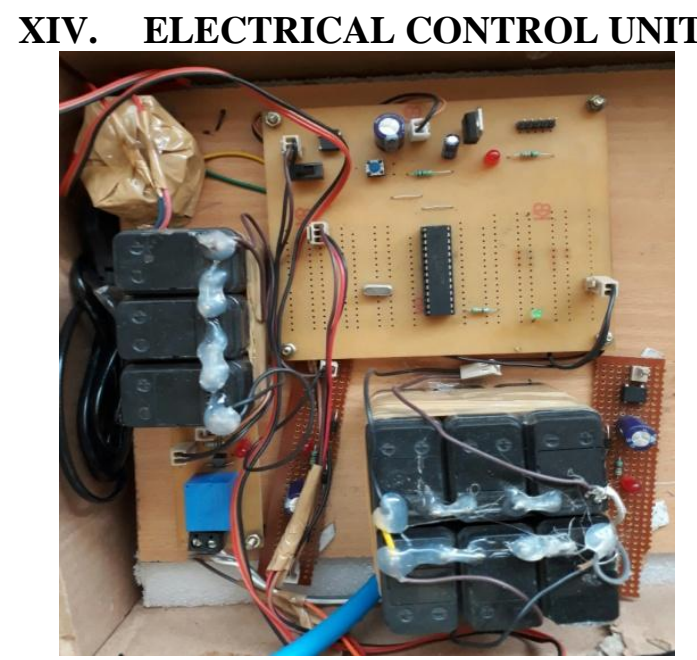

The electrical controller unit is used to controller the speed of the vehicle under micro controller and two rechargeable batteries with the help of transformer, relay, voltage regulator, capacitor, bridge rectifier.

\section{DESIGN CALCULATIONS}

Maximum pressure - 10 bar

Atmospheric pressure - 1.013 bar

Operating pressure -5.3 bar

Discharge - $0.00191 \mathrm{~m} 3 / \mathrm{sec}$

Maximum power $=2 \pi \mathrm{NT} / 60$

$=2 \pi \times 300 \times 61 / 60$

$=1916.37$ watt

Required Power $=\mathrm{Q} \times \Delta \mathrm{p}$

$=0.00191 \times 5.3 \times 10^{\wedge} 5$

$=1012.3$ wattTION

\section{CONSTRUCTION AND WORKING}

\section{Construction}

It consists of chassis, pneumatic ratchet which is fixed on the bottom of chassis with help of 
c clamp. 12V DC air compressor used to compressor to the atmospheric air which is operated on $12 \mathrm{~V}$ batteries. The air storage tank is mounted at the frame of chassis. The shaft or axle are fixed on the chassis with the help of pedestal, which consist of bearing enclosed in the casing. The chain drive are used to transmit the power from ratchet to rear axle.

\section{Working}

In this pneumatic cycle initially the person will start the cycle with the slight push and compression lever in pressed position and the ratchet will start. As the ratchet starts the compression lever is pressed. It works on the energy conversion principle the air is compressed and stroke in the tank. It contains potential energy and this potential energy of air is converted into kinetic energy and power is developed.

Once the power is to be developed the sprocket will start rotating by using chain drive which transmits the power from sprocket to rear axle. Axle rotates the rear wheel and tricycle start running. By using accelerator we increase and decrease the speed of tricycle.

\section{PNEUMATIC TUBE (HOSSES)}

The main function of pneumatic tube is to carry compressed air from air storage tank through the pressure regulating valve and material is nylon.

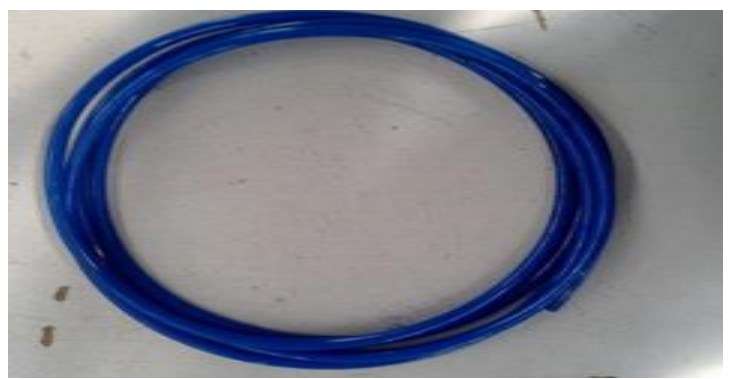

\section{PROBLEM FACED WHILE DESIGN AND FABRICATION}

1) Axle

At the time of first design of axle, when we apply the brakes the axle get unwound by braking force. Then at the next design, there was a minute ply between the split axle due to which the thread get weared.

\section{2) Brake}

In the initial stage, we are looking for the disc braking system. But it is very costly and not easily available in the market, so we think about its alternative and use band braking system.

\section{3) Vibration}

Vibration occurs in the tricycle due to the transmitting the power from ratchet to rear axle.

\section{ADVANTAGES}

1. It is flexible and easy to drive and control due to its simple construction as that of a bicycle and light weight.

2. It is automatic as well as manual in operation.

3. In case if the automatic operation fails or discontinues in case of inadequate air supply, the operation can be switched to manual mode

3. It has compact structure and aesthetic shape.

4. It is intended for indoor and outdoor

\section{Disadvantages}

1) It cannot be used for long distance.

2) It cannot be used effectively in uneven road conditions due to the possibility of disturbances in the alignments.

3) Lack of braking system.

4) Vibrations in the system can cause disturbances in the running mechsnism.

\section{Driving Guidance}

1. Before starting, please check the following items:

Check the pressure in the air tank, fill up the tank if it is not enough.

Check the pressure regulator, rear brake to make available reliable.

Check the transmission system.

Check whole body to make sure that all the parts are fixed tightly .

. Fill up the tank with air at pressure up to6.5 bar.

\section{After checking, the pneumatic circuit starts.} Open the needle valve for starting the airflow.

Open FRL or pressure regulator and fixed it to required pressure.

Pull the clutch cable for compress the ratchet lever.

$>$ When compressed lever ratchet starts rotating and transmitting the power.

$>$ 3. Driving and parking;

$>$ When the tricycle start running apply pressure as per requirement.

$>$ When the clutch cable was released the ratchet should stop working.

$>$ Close the needle valve and shut down the air compressor. 
XX. MAINTENANCE AND SERVICE

1. Start the air compressor fill the air and drive it.

2. Maintain the lubricant in FRL or pressure regulator.

3. If the pneumatic ratchet has abnormal noise, get it check by professional service provider.

4. Front and rear brake adjustment Adjust rear brake using adjusting screw. When fasten hold the brake bar, the wheel should not be turned around. The brake rubber should be back to its position at once when unfold the brake bar. If the surface of the rubber is worn hardly, change it.

5. Keep the vehicle clean, and to avoid, higher temperature and corrosive air places.

\section{Environmental Condition}

$>$ When tricycle is not in use at that time, tricycle should be kept away from rain water, combustible and chemical corrosive products.

$>$ When there is no use of tricycle for long time then drain the air tank.

$>$ When there is no use of tricycle

\section{TROUBLESHOOTING}

1) The pneumatic ratchet does not start

$\checkmark \quad$ Check the air tank.

$\checkmark$ Check the battery connections

$\checkmark$ Make sure needle valve is in open position.

2) Pneumatic ratchet starts but fail to run at high speed.

$\checkmark \quad$ Check if the lever is fully compressed.

$\checkmark$ Adjust FRL or pressure regulator.

$\checkmark$ Adjust pressure as per requirement.

$\checkmark \quad$ The water filter may need cleaning.

3) Pneumatic ratchet runs but has no power or acceleration.

$\checkmark \quad$ Check the lever in compressed position.

$\checkmark \quad$ The water filter may need cleaning.

$\checkmark \quad$ Adjust pressure regulating valve.

4) Pneumatic ratchet fails to run smoothly.

$\checkmark \quad$ Check the lever in fully in compressed position.

$\checkmark \quad$ Adjust pressure regulating valve.

\section{CONCLUSION}

Even though the vehicle is in its early stage of development, it holds a lot of promise and provides scope for further research. Considerable efforts have been focused on the better understanding of various design developments in bicycle. Various forms of bicycle in the past history through which the existing form has evolved are discussed in this paper. The different empirical methods of transmission of human power on the pedal to the rotation of the wheels are discussed and the major advantages and disadvantages of these transmission methods are listed out.
Generally, new mechanisms should be developed such that the design should be eco- friendly and more energy efficient. The project presented has involved the development and implementation of automatic transmissions for bicycles. The motivation of this work is to implement this idea in pneumatic featured bicycles with a suitable air control. The automatic transmission can be also used in 3 and 4 speed versions by altering few changes in the program. Therefore from the above calculations it is evident that the forces exerted by the cylinders are optimum to move the shifting levers (pedals). According to the achieved results, the suggested mechanism is realizable and workable. Using the simplest mechanism and required hardware enables to convert the old traditional gear shifting mechanism to semi automatic one. The application of this mechanism leads to make the driving process easier, reduces the risk of destabilizing the car, the lap/stage time, and the chance of miss shifting.

\section{FUTURE SCOPE} arrangement.

In future we can use flexible seating

In this pneumatic Bicycle we can use high power motor.

We can use suspension system.

This bicycle is very flexible and can be modified according to once interest.

In future this bicycle can used for normal people.

\section{REFERENCES}

[1]. B.R.Singh, O. Singh,Study of Compressed Air Storage System as Clean Potential Energy for 21st Century, Global Journal of researches in engineering Mechanical and mechanics engineering, 12(1), 2012

[2]. Y.M.Kim,D. Favrat,Energy and energy analysis of a micro compressed air energy storage and air cycle heating and cooling system. Energy, 35 (1), (2010), 13-20.

[3]. S.S. Verma, Air Powered Vehicles, The Open Fuels \& Energy Science Journal, (2008)1, 54-56.

[4]. 11. J.P.Yadav,B. R. Singh, Study and Fabrication of Compressed Air Engine, Samriddhi, 2(1), (2011), 1-8.

[5]. www.tramwayinfo.com/tramways/Articles/ Compair2.htm accessed 23 June 2009

[6]. Bossel U 2005.Thermodynamic Analysis of Compressed Air Vehicle Propulsion European Fuel Cell Forum.

[7]. Papson, F. Creutzig, L. Schipper, Compressed air vehicles: a drive cycle analysis of vehicle performance, environmental impacts, and economic costs, 
2010 Annual meeting of the transportation research board and publication in the transportation research record.

[8]. S.S. Verma, Air Powered Vehicles, The Open Fuels \& Energy Science Journal, (2008)1, 54-56.

[9]. J.P.Yadav,B. R. Singh, Study and Fabrication of Compressed Air Engine, Samriddhi, 2(1), (2011), 1-8.

[10]. J.D. Van de Venn, M.W. Olson, and P.Y. Li, "Development of a hydro-mechanical hydraulic hybrid drive train with independent wheel torque

[11]. control for an urban passenger vehicle" In Proceedings of the International Fluid Power Exposition, pp. 11- 15, 2008.

[12]. S. Trajkovic, A. Milosavljevic, P. Tunstall, B. Johansson,"FPGA Controlled Pneumatic Variable Valve Actuation", SAE Paper 2006-01-0041,2006.

[13]. Sasa Trajkovic, "The Pneumatic Hybrid Vehicle-A New Concept for Fuel Consumption Reduction", Doctoral Thesis, 2010.

[14]. JP Yadav and Bharat Raj Singh, "Study and Fabrication of Compressed Air Engine", SJPSET: ISSN: 2229-7111, Vol. 2, Issue 1, 2011 